\title{
Role of Angiotensin-Converting Enzyme and Vitamin D Receptor Gene Polymorphisms in Cancer Anorexia-Cachexia Syndrome
}

\author{
${ }^{1}$ Ariele Fabris, ${ }^{2}$ Paolo Biagioni, ${ }^{3}$ Tiziana Punzi, ${ }^{3}$ Gabriele Morucci, \\ ${ }^{3}$ Massimo Gulisano, ${ }^{3}$ Stefania Pacini and ${ }^{4}$ Marco Ruggiero \\ ${ }^{1}$ Department of Medizinische Klinik, Faculty of Medicine, Universität Koln Kreiskrankenhaus Gummersbach, Germany \\ ${ }^{2}$ Department of Nutritional Unit, Faculty of Medicine of Misericordia e Dolce Hospital, Prato, Italy \\ ${ }^{3}$ Department of Anatomy, Histology and Forensic Medicine, \\ ${ }^{4}$ Department of Experimental Pathology and Oncology, \\ Faculty of Medicine, Università degli Studi di Firenze, Firenze, Italy
}

Received 2012-07-23, Revised 2012-08-02; Accepted 2012-08-02

\begin{abstract}
The ubiquitin-proteasome pathway is a crucial connection between aberrant immune system activation, systemic inflammation and Cancer Anorexia-Cachexia Syndrome (CACS), a syndrome that culminates in hyper-activation of the ubiquitin-proteasome pathway. Angiotensin directly up-regulates this pathway, while vitamin D down-regulates it indirectly through the insulin-like growth factor-1 pathway. We investigated the genetic predisposition towards CACS in a cancer population, examining Insertion/Deletion (I/D) polymorphism of angiotensin-converting enzyme gene and FokI and BsmI polymorphisms of vitamin D receptor gene. Sixty-two cancer patients were recruited and divided into three groups: primary cachectic ( $\mathrm{C} 1, n=14$; dysmetabolic body weight loss $\geq 5 \%$ in 6 months); secondary cachectic (C2, $n=34$; similar weight loss, mechanic or iatrogenic origin); and non-cachectic (NC, $n=$ 16). $\mathrm{C} 2+\mathrm{NC}$ were merged in the control group. The three groups showed significant differences in average prognostic inflammatory nutritional index ( $\mathrm{C} 1: 26.4 \pm 23.4 ; \mathrm{C} 2: 5.4 \pm 5.6 ; \mathrm{NC}: 0.37 \pm 0.5)$, Creactive protein serum levels $(\mathrm{C} 1: 6.6 \pm 2.1 ; \mathrm{C} 2: 2.4 \pm 2.2 ; \mathrm{NC}: 1.0 \pm 2.0 \mathrm{mg} / \mathrm{dl})$, albumin serum levels $(\mathrm{C} 1$ : $3.1 \pm 0.6 ; \mathrm{C} 2: 3.5 \pm 0.4 ; \mathrm{NC} 3.7 \pm 0.6 \mathrm{~g} / \mathrm{dl}$ ), weight loss (C1: 22 $\pm 8 ; \mathrm{C} 2: 15 \pm 6.7$; $\mathrm{NC} 5 \pm 6 \%)$ and life expectancy (C1: $6.4 \pm 3.3 ; \mathrm{C} 2: 25 \pm 28$; NC: $45 \pm 25$ months). However, none of the chosen polymorphisms showed any statistically significant correlation with CACS. The complexity of the changes of the immune system in the chronic inflammation state associated with CACS is far greater than expected and further studies are required to identify genetic independent markers of progression toward CACS.
\end{abstract}

Keywords: Weight Loss, Prognosis, Inflammation

\section{INTRODUCTION}

Cancer Anorexia-Cachexia Syndrome (CACS) is a dramatic and debilitating occurrence that can be observed at any stage of malignancy and has been described as a clinical syndrome accompanying cancer since ancient times (Bennani-Baiti and Walsh, 2009). We recently demonstrated that cancer patients with CACS have higher C-Reactive Protein (CRP) levels compared with non-cachectic cancer patients (Punzi et al., 2012), thus reinforcing the hypothesis that the chronic inflammatory state commonly observed in advanced cancers is linked to the aetiology of CACS (MacDonald, 2011). Aberrant immune system activity is a crucial aspect of the chronic systemic inflammation associated with CACS and it triggers a vicious cycle leading to further tumour growth and metastases. Although the interconnections between aberrant immune system activity and CACS are multifaceted, two specific pathways appear to be prominent; the ubiquitinproteasome pathway (Camps et al., 2006) and the vitamin $\mathrm{D}$ axis that includes vitamin $\mathrm{D}$, the polymorphic vitamin D receptor (VDR), the vitamin D-binding protein (or Gc-protein) and its derivative, Gc protein-derived Macrophage Activating Factor (GcMAF), one of the most potent stimuli of the immune system (Strohle et al., 2010; Ruggiero and Pacini, 2011). 


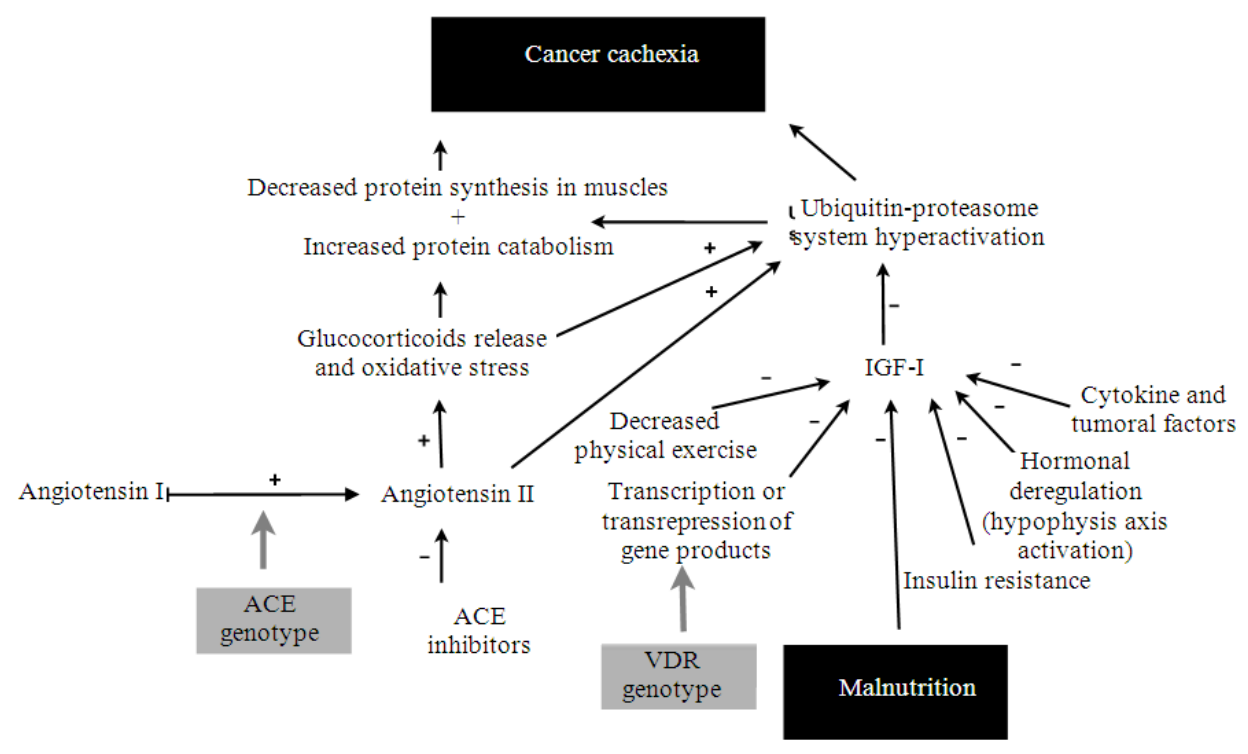

Fig. 1. Angiotensin-Converting Enzyme (ACE) and Vitamin D Receptor (VDR) genotypes in cancer anorexia-cachexia syndrome

As schematically illustrated in Fig. 1, the association between the ubiquitin-proteasome pathway, Angiotensin Converting Enzyme (ACE) and VDR polymorphic genotypes, CACS and the immune system is a complex one. In this regard, at the 2007 annual meeting of the American Society of Clinical Oncology, Vigano et al. (2007) presented a challenging work entitled "AngiotensinConverting Enzyme Gene Polymorphism (ACEGP) and Cancer Cachexia (CC): Is there a link?" (Vigano et al., 2007). In fact, it had been previously demonstrated that angiotensin I (ATI)-induced protein degradation was inhibited by the ACE inhibitor imidapril and/or the proteasome inhibitors lactacystin or MG132 (Sanders et al., 2005). In Addition, it was demonstrated that angiotensin II (ATII) suppressed hepatic expression of Insulin-Like Growth Factor-1 (IGF-1) (Delafontaine and Akao, 2006) and increased cortisol serum levels (Ortiz et al., 2010). These two events act synergistically on muscle protein breakdown with consequent liberation of free amino acids via the ubiquitin-proteasome pathway. Therefore, considering the pro-catabolic effects of ATII on skeletal muscle, mainly via the ubiquitin-proteasome pathway, our hypothesis was that ACE gene polymorphisms could be associated with different prognosis in CACS patients.

If ACE gene polymorphisms may be associated with a pro-catabolic effect, VDR gene polymorphisms on their part could be associated with an anti-catabolic effect. In fact, activated VDR acts as a transcriptional factor forming a heterodimer with the retinoid-X receptor and then binding to response elements on DNA, resulting in expression or repression of specific target genes (Moore et al., 2006). Among these, the IGF-1 transcriptional pathway falls under the target of VDR modulation (Jurutka et al., 2001). IGF-1, a potent anabolic signal, directly inhibits the ubiquitinproteasome system, thus, at least hypothetically, counteracting the effects of ACE product (Stitt et al., 2004). The ubiquitin-proteasome pathway appears thus to be located at a critical control point with ACE and VDR gene polymorphic genotypes possibly associated with opposite effects on the anabolic/catabolic balance.

Therefore, in this study we determined Insertion/Deletion (I/D) ACE gene polymorphism and FokI and BsmI VDR gene polymorphisms in cancer patients in order to establish whether specific polymorphic genotypes could be associated with the prognosis.

\section{MATERIALS AND METHODS}

After giving their informed consent, sixty-two cancer patients were randomly recruited in the Nutritional Unit of the Misericordia e dolce hospital in Prato, Italy. Age, gender, stage, primary cancer localization and ongoing therapy were randomly chosen. We divided the enrolled subjects into the following three groups: primary Cachectic (C1), secondary Cachectic (C2) and nonCachectic (NC). The ranking criteria followed the guidelines set by the Italian Association of Medical Oncology (AIOM) in 2007 and are summarized in Table 1 (AIOM, 2008). Accordingly, we had 14 patients in the $\mathrm{C} 1$ group, 32 in the $\mathrm{C} 2$ group and 16 in the $\mathrm{NC}$ group. 
Table 1. Criteria for diagnosis of primary and secondary CACS, AIOM 2007

\begin{tabular}{l}
\hline Primary CACS \\
\hline Loss $\geq 5 \%$ of pre-illness weight within the last 6 months plus \\
Decreased muscle strength \\
Fatigue \\
Anorexia \\
Low lean mass index \\
Biochemichal alterations: \\
Increase in cytokine levels \\
Hb $<12$ mg/dl \\
Albumin $<3.2$ mg kg ${ }^{-1}$ \\
Additional criteria for diagnosis of secondary CACS \\
CACS plus clinical evidence of \\
Gastrointestinal obstruction \\
Chemotherapeutic treatment, radiation therapy \\
Post-interventional malabsorption sindrome \\
CACS, cancer anorexia-cachexia syndrome; AIOM, \\
Associazione Italiana di Oncologia Medica; \\
Hb, haemoglobin
\end{tabular}

As reported in Table 1, the diagnosis of cachexia followed the documented loss of $5 \%$ or more of body weight in the 6 months preceding the diagnosis of cancer. Despite the broad lack of consensus for this quantification, with many Authors assuming occurrence of CACS only after $10 \%$ body weight loss in 6 months, we postulated that in an actual clinical frame an early threshold was preferable. Secondary CACS depicted the frequent situation of a wasting syndrome derived from precise detectable causes. The two main tools to distinguish $\mathrm{C} 1$ from $\mathrm{C} 2$ were, therefore, targeted anamnesis and endoscopy/imaging. The unknowing patient, who involuntarily was losing weight with a conserved appetite or with a first manifestation of anorexia, was the prototype patient fitting the $\mathrm{C} 1$ criteria. The dyspeptic, dysphagic patient, who was losing weight after chemotherapy, surgery, radiation therapy, or because of severe stenosis at the level of the gastrointestinal tract, was a fitting model for $\mathrm{C} 2$. $\mathrm{NC}$ patients sometimes also lost weight. In this case, however, it was generally a therapeutic weight loss aiming to prevent complications in poly-morbid conditions, like heart failure, diabetes, respiratory distress.

We analyzed the three groups as separate entities during the epidemiological study, but we reduced the last two to a single one, the non-primary CACS group $(\mathrm{NC}=$ $\mathrm{C} 2+\mathrm{NC}$ ), for the study of polymorphic genotypes, considering this as the control group with no presumable genetic predisposition towards weight loss. Each enrolled patient underwent accurate clinical examination, blood collection and DNA sampling. The clinical data of interest included age, tumor type, stage, pre-illness weight and timing of weight loss. Weight measurement in the ambulatory unit concluded the routine. Venous blood samples were taken and serum levels of CRP, prealbumin, albumin and alpha-1-acid-protein were determined in the clinical laboratories of the hospital. We then calculated the Prognostic Inflammatory and Nutritional Index (PINI) score for each patient. Regrettably, approximately one of two patients taking part in the study deceased during the 2 year observation period. A retrospective analysis of life expectancy could therefore be traced, starting from the first day of cancer diagnosis.

DNA sampling was done on finger prick samples of approximately $50 \mu \mathrm{l}$. DNA extraction and purification were performed by QIAamp ${ }^{\circledR}$ DNA Blood Mini Kit (QIAGEN S.p.a., Italy). Purified DNA was then examined for FokI and BsmI VDR gene polymorphism and I/D ACE gene polymorphism after polymerase chain reaction amplification (SuperMini Cycler ${ }^{\circledR}, \quad \mathrm{Mj}$ Research, Inc., USA) using specific primers and the AccuPrime Supermix Kit (Invitrogen, Carlsbad, CA, USA) (Punzi et al., 2012).

Investigation of the $\mathrm{ACE}$ gene $\mathrm{I} / \mathrm{D}$ polymorphism required no restriction enzymes; once amplified, the genetic sequence of interest had different lengths, depending on the presence (I) or absence (D) of the fragment $288 \mathrm{bp}$ length. On the contrary, to determine the allelic characteristic of the VDR gene, each amplified DNA fragment was treated with appropriate restriction enzymes (Punzi et al., 2012). The restriction products of FokI and BsmI were sorted as $F$ and $f$ and $B$ and $b$ respectively, where capital letters indicate an absence of restriction sites and lowercase letters indicate their presence.

\section{RESULTS}

As expected, the clinical threefold subdivision of patients produced radically different groups in terms of average weight loss, intensity of inflammatory reaction, nutritional status, PINI score and life expectancy. It is important to notice that differences in average age and stage proved to be non-significant; we consider this observation of clinical relevance since it reinforces the notion that CACS is a stochastic event. C1 patients had the highest systemic inflammation, lowest nutritional status and dramatically poorest prognosis (Table 2). As previously described by our research group (Punzi et al., 2012), CRP proved to be one of the most reliable and economic blood markers for CACS that a standard clinical laboratory can study (Mahmoud and Rivera, 2002). A standard nutritional status assessment usually includes the determination of albumin serum level, despite the open discussion regarding which albumin threshold should be chosen for the diagnosis of malnutrition. 
Table 2. Patients' data

\begin{tabular}{|c|c|c|c|c|c|c|}
\hline & \multicolumn{2}{|l|}{$\mathrm{C} 1$} & \multicolumn{2}{|l|}{$\mathrm{C} 2$} & \multicolumn{2}{|l|}{$\mathrm{NC}$} \\
\hline & Mean \pm SD & $n$ & Mean \pm SD & $n$ & Mean \pm SD & $N$ \\
\hline$\overline{\text { Age (years) }}$ & $66.9 \pm 8.66$ & 14 & $66.8 \pm 11.6$ & 32 & $59.9 \pm 10.6$ & 16 \\
\hline Stage & $3.6 \pm 0.6$ & 14 & $3.6 \pm 0.6$ & 32 & $3.4 \pm 0.9$ & 16 \\
\hline Gender & $43 \% \mathrm{~F}$ & 14 & $37 \% \mathrm{~F}$ & 32 & $50 \% \mathrm{~F}$ & 16 \\
\hline \%Weight loss in 6 months & $21.0 \pm 7.9$ & 14 & $15.4 \pm 6.7$ & 32 & $5.1 \pm 6.2$ & 16 \\
\hline CRP (mg/dl) & $6.6 \pm 6.3$ & 9 & $2.4 \pm 2.2$ & 29 & $1.0 \pm 2.0$ & 16 \\
\hline Albumin (mg/dl) & $3.1 \pm 0.6$ & 10 & $3.5 \pm 0.4$ & 29 & $3.7 \pm 0.6$ & 15 \\
\hline PINI score & 28 & 9 & 4 & 20 & 0.98 & 11 \\
\hline $\begin{array}{l}\text { Average survival time after } \\
\text { diagnosis of cancer (months) }\end{array}$ & $6.4 \pm 3.3$ & 9 & $26.1 \pm 27.6$ & 12 & $45.3 \pm 25.0$ & 7 \\
\hline
\end{tabular}

$\overline{\mathrm{C} 1}$, high risk; $\mathrm{C}$, intermediate risk; $\mathrm{C}$, normal. $\mathrm{F}$, female

Table 3. Genotype frequencies in primary CACS and control groups

\begin{tabular}{lllll}
\multicolumn{1}{c}{ groups } & \multicolumn{3}{c}{$\mathrm{C}+\mathrm{NC}$} & $\mathrm{C} 1$ \\
VDR gene & Genotype & $(n=48)$ & $(n=14)$ & $\mathrm{p}$ \\
\hline polimorphysms & & & & \\
FokI & $\mathrm{FF}$ & 0.28 & 0.36 & 0.81 \\
& $\mathrm{Ff}$ & 0.64 & 0.57 & \\
BsmI & $\mathrm{ff}$ & 0.08 & 0.07 & \\
& $\mathrm{BB}$ & 0.10 & 0.07 & 0,87 \\
& $\mathrm{Bb}$ & 0.53 & 0.50 & \\
ACE gene & $\mathrm{bb}$ & 0.37 & 0.43 & \\
polymorphisms & $\mathrm{DD}$ & 0.45 & 0.50 & 0,62 \\
& $\mathrm{ID}$ & 0.38 & 0.43 & \\
\hline C1 & $\mathrm{II}$ & 0.17 & 0.07 & \\
\hline
\end{tabular}

$\mathrm{C} 1$, primary cancer anorexia-cachexia syndrome (CACS); $\mathrm{C} 2+$ $\mathrm{NC}$, no presumable genetic disposition towards CACS; VDR, vitamin $\mathrm{D}$ receptor; ACE, angiotensin-converting enzyme

Table 4. Allele frequencies in primary CACS and control groups

\begin{tabular}{lllll}
\hline $\begin{array}{l}\text { VDR } \\
\text { polymorphisms }\end{array}$ & Alleles & $\begin{array}{l}\mathrm{C} 2+\mathrm{NC} \\
(n=48)\end{array}$ & $\begin{array}{l}\mathrm{C} 1 \\
(n \text { 14) }\end{array}$ & $p$ \\
\hline FokI & $\mathrm{F}$ & 0.60 & 0.68 & 0.64 \\
& $\mathrm{f}$ & 0.40 & 0.32 & \\
BsmI & $\mathrm{B}$ & 0.36 & 0.32 & 0.63 \\
ACE polymorphisms & $\mathrm{b}$ & 0.64 & 0.68 & \\
& $\mathrm{D}$ & 0.64 & 0.71 & 0.41 \\
& $\mathrm{I}$ & 0.36 & 0.29 & \\
\hline
\end{tabular}

$\overline{\mathrm{C} 1 \text {, primary cancer anorexia-cachexia syndrome (CACS); } \mathrm{C} 2+}$ $\mathrm{NC}$, no presumable genetic disposition towards CACS; VDR, vitamin D receptor; ACE, angiotensin-converting enzyme

We set the cutoff for malnutrition at $3.5 \mathrm{mg} / \mathrm{dl}$ albumin (Harrison, 1998) and at $3.2 \mathrm{mg} / \mathrm{dl}$ for a diagnosis of severe malnutrition. The critics for albumin as a nutritional marker mainly revolve around two observations, namely that hepatic protein synthesis reprioritization in the acute inflammatory response is per se sufficient to precipitate albumin serum levels, despite normal nutritional status and that compensatory mechanisms keep albumin levels high during prolonged insufficient protein intake through depletion of skeletal muscle tissue. Although high CRP levels are good indexes for systemic inflammation, poor levels of albumin cannot distinguish starvation from chronic systemic inflammation. Therefore, in order to draw a comprehensive picture of the three patient groups, we combined the collected blood values into a single score, the PINI score a reliable tool capable of estimating the risk of complications during hospitalization of chronically ill patients (Yates, 1980). PINI is calculated by dividing the product of serum alpha-1-glycoprotein and CRP levels by that of albumin and pre-albumin.

Prognostic Inflammatory and Nutritional Index:

$$
\frac{\text { alpha }-1 \text { acid }- \text { glycoprotein }(\mathrm{mg} / \mathrm{dl}) \text { x CRP }(\mathrm{mg} / \mathrm{dl})}{\text { albumin }(\mathrm{g} / \mathrm{dl}) \text { x prealbumin }(\mathrm{mg} / \mathrm{dl})}
$$

Where:

PINI $>30=$ predicts a very high risk of complications during hospitalization [21-30] predicts a high risk of complications during hospitalization

[11-20] = Predicts an intermediate risk

$[1-10]=$ Predicts a low risk

$<1=$ Normal

As reported in Table 2, the $\mathrm{C} 1$ group fell in the highrisk category, $\mathrm{C} 2$ in the intermediate and $\mathrm{NC}$ in the normal. The survival rate of the three groups confirmed the nutritional prognosis.

Given the significant differences of the three populations, in order to investigate the genetic predisposition towards CACS, we isolated the $\mathrm{C} 1$ group $(n=14)$ and created a reference group merging $\mathrm{C} 2$ and NC pools $(n=48)$, which presumably had no genetic 
predisposition towards CACS. The study of genotypic frequency results from the proportion between the number of subjects harboring a specific genotype and the total number of subjects. Below is the formula for the frequency of an exemplificative FF genotype; genotype frequencies in primary CACS and control groups are shown in Table 3:

$$
\begin{aligned}
& \text { FF genotype }=\text { number of FF subjects } \\
& / \text { total examined subjects }(\mathrm{FF}+\mathrm{Ff}+\mathrm{ff})
\end{aligned}
$$

Comparing the genotype frequencies of the VDR gene between the group of primary cachectic patients and the control group, no significant difference could be found $(p>0.05)$. Comparing the genotype frequencies of the ACE gene between the same pools of patients, the same result was obtained. The distribution of allele frequencies was then calculated both for the VDR and ACE gene polymorphisms on the basis of genotype frequencies (Table 4). Below is the formula for calculating allele frequency:

$$
\begin{aligned}
& \mathrm{F} \text { allele frequency }=\text { genotype } \\
& \mathrm{FF} \text { frequency }+1 / 2 \mathrm{Ff} \text { genotype frequency } \\
& \text { f allele frequency }=1-\mathrm{F} \text { allele frequency }
\end{aligned}
$$

Allele distribution for both ACE and VDR genes showed no significant difference between the primary cachectic group and the control group, for any of the studied polymorphisms (Table 4).

\section{DISCUSSION}

Genetics is a promising field for the study of predisposition towards CACS, because CACS itself is an apparently stochastic event, occurring at random among individuals who are not significantly different in terms of age, stage and tumor type as confirmed in this study. Nevertheless, according to the results of our observations, the answer to the question "AngiotensinConverting Enzyme Gene Polymorphism (ACEGP) and Cancer Cachexia (CC): Is there a link?" appears to be negative. In fact, both allele frequencies and genotypic frequencies of the ACE gene polymorphisms were not significantly associated with clinical progression of CACS. A similar conclusion can be drawn for VDR gene polymorphisms. These conclusions notwithstanding, we cannot rule out the possibility that different results could be obtained by increasing the size of the sample to be examined. In addition, although the random selection of patients was a precise choice of this study reflecting the clinical actuality of most hospitals, we cannot rule out the possibility that in certain sub-groups of CACS patients the results might be different.

\section{CONCLUSION}

In conclusion, our study demonstrates that the complexity of the changes of the immune system in the chronic inflammation state associated with CACS (Khatami, 2011) is far greater than expected and further studies are required to identify genetic independent markers of progression toward CACS that, as of today, remains a stochastic, unpredictable event.

\section{ACKNOWLEDGEMENT}

This study was supported by grant from PRIN 2009, N. 447, area 05 (to S. P. and M. R.)

\section{REFERENCES}

AIOM, 2008. Trattamento e prevenzione della cachessia neoplastica. Associazione Italiana Oncologia Medica, Italia.

Bennani-Baiti, N. and D. Walsh, 2009. What is cancer anorexia-cachexia syndrome? A historical perspective. J. R. Coll. Physicians Edinb., 39: 257262. PMID: 20608345

Camps, C., V. Iranzo, R.M. Bremnes and R. Sirera, 2006. Anorexia-cachexia syndrome in cancer: Implications of the ubiquitin-proteasome pathway. Support Care Cancer, 14: 1173-1183. PMID: 16819628

Delafontaine, P. and M. Akao, 2006. Angiotensin II as candidate of cardiac cachexia. Curr. Opin. Clin. Nutr. Metab. Care, 9: 220-224. PMID: 16607120

Harrison, T.R., 1998. Principles of Internal Medicine. 13th Edn., McGraw Hill, New York, ISBN-10: 0070645183, pp: 510.

Jurutka, P., G. Whitfield, J.C. Hsieh, P.D. Thompson and C.A. Haussler et al., 2001. Molecular nature of the vitamin D receptor and its role in regulation of gene expression. Rev. Endocr. Metab. Disord., 2: 203216. PMID: 11705326

Khatami, M., 2011. Unresolved inflammation: Immune tsunami" or erosion of integrity in immuneprivileged and immune-responsive tissues and acute and chronic inflammatory diseases or cancer. Expert. Opin. Biol. Ther., 11: 1419-1432. PMID: 21663532 
MacDonald, N., 2011. Chronic inflammatory states: Their relationship to cancer prognosis and symptoms. J.R. Coll. Physicians Edinb., 41: 246253. PMID: 21949925

Mahmoud, F.A. and N.I. Rivera, 2002. The role of Creactive protein as a prognostic indicator in advanced cancer. Curr. Oncol. Rep., 4: 250-255. PMID: 11937016

Moore, D., S. Kato, W. Xie, D.J. Mangelsdorf and D.R.Schmidt et al., 2006. International union of pharmacology. LXII. The NR1H and NR1I receptors: Constitutive androstane receptor, pregnene $\mathrm{X}$ receptor, farnesoid $\mathrm{X}$ receptor alpha, farnesoid $X$ receptor beta, liver $X$ receptor alpha, liver $\mathrm{X}$ receptor beta and vitamin $\mathrm{D}$ receptor. Pharmacol. Rev., 58: 742-759. PMID: 17132852

Ortiz, R.M., H. Kobori, D. Conte and L.G. Navar, 2010. Angiotensin II-induced reduction in body mass is Ang II receptor mediated in association with elevated corticosterone. Growth Horm. IGF Res., 20: 282-288. PMID: 20483644

Punzi, T., A. Fabris, G. Morucci, P. Biagioni and M. Gulisano et al., 2012. C-reactive protein levels and vitamin $\mathrm{D}$ receptor polymorphisms as markers in predicting cachectic syndrome in cancer patients. Mol. Diagn. Ther., 16: 115-124. PMID: 22497530
Ruggiero, M. and S. Pacini, 2011. The vitamin D axis in chronic kidney disease-State of the art and future perspectives. Europ. Nephrol., 5: 15-19.

Sanders, P.M., S.T. Russell and M.J. Tisdale, 2005. Angiotensin II directly induces muscle protein catabolism through the ubiquitin-proteasome proteolytic pathway and may play a role in cancer cachexia. Br. J. Cancer, 93: 425-434. PMID: 16052213

Stitt, T., D. Drujan, B. Clarke, F. Panaro and Y. Timofeyva et al., 2004. The IGF-1/PI3K/Akt pathway prevents expression of muscle atrophyinduced ubiquitin ligases by inhibiting FOXO transcription factors. Mol. Cell., 14: 395-403. PMID: 15125842

Strohle, A., K. Zanker and A. Hahn, 2010. Nutrition in oncology: The case of micronutrients (review). Oncol. Rep., 24: 815-828. PMID: 20811659

Vigano, A.A., N. Hamel, J. Morais, W. Foulkes and R. Kilgour et al., 2007. Angiotensin-converting enzyme gene polymorphism (ACEGP) and Cancer Cachexia (CC): Is there a link? J. Clinical Oncol.

Yates, J.W., B. Chalmar and F.P. Mc Kegney, 1980. Evaluation of patients with advanced cancer using the Karnofsky performance status. Cancer, 45: 2220-2224. PMID: 7370963 